\title{
Chapter 4 \\ Facts and Challenges Regarding Grounded Theory, the ICF and Ethical Issues
}

\begin{abstract}
Regarding methodology and methods, grounded theory becomes the major tool. Thereby, Kathy Charmaz is the leading scholar I am referring to. As grounded theory is discussed on a very broad basis in the scientific community, also critical voices are included. However, it becomes clear that I am following the constructivist tradition and I am basing my research on these epistemological grounds. The interpretive character of the research method is also highlighted.

As a second aspect, I am describing and discussing the International Classification of Functioning, Disability and Health - Child and Youth Version (ICF-CY) in detail. The ICF-CY is presented, as it has been used as a research tool in the beginning of the study. At the same time, the classification is critically examined. This gives me the chance to introduce critical voices and open up the discussion referring to points that are relevant for the study (special emphasis is put on the environmental factors of the classification).

Finally, this qualitative study is based on interviews (children with disabilities, parents, teachers, experts). Thus, individual as well as focus group interviews were the main sources of information. This is the reason why the last part of this chapter is dealing with ethical concerns.
\end{abstract}

\section{Grounded Theory}

\begin{abstract}
Attempts to close the gap between theory and research have concentrated principally on the improvement of methods for testing theory, and sociologists, as well as other social and behavioural scientists, have been quite successful in that endeavour. Attempts to close the gap from the 'theory side' have not been nearly so successful. In fact, 'grand theory' is still so influential and prevalent that for many researchers it is synonymous with 'theory' - and so they think of 'theory' as having little relevance to their research. (Glaser and Strauss 1967/2008, vii)
\end{abstract}

Glaser and Strauss wrote "The Discovery of Grounded Theory" in an effort to change this perspective of theory, which is not directly connected to research, to a theory that is directly related to research. "The Discovery of Grounded Theory (1967) provided a powerful argument that legitimized qualitative research as a cred- 
ible methodological approach in its own right rather than simply as a precursor for developing quantitative instruments" (Charmaz 2006, 6).

Grounded theory is often referred to as a methodology as well as a method. The correct use of terms would be to distinguish between grounded theory and grounded theory method. In this way, grounded theory methods are used to develop grounded theory (Bryant and Charmaz 2007). "As a heuristic device, it may be helpful to view objectivist and grounded theory as located on two ends of a continuum. [...]. Using grounded theory is a process; the method itself is in process. Its fluidity and flexibility inhere in the method itself" (Charmaz 2009, 137). In the book at hand, grounded theory is referred to as the underlying methodology as well as a method to develop a theory.

The development of grounded theory is described in the Sage Dictionary of Social Research Methods as follows:

Grounded theory is an approach to research that was developed in response to concerns over the predominance of quantitative methods in social sciences and the tendency for research to be undertaken to test existing grand theories. Glaser and Strauss (1967: p. vii cited in Harding 2006, 131) perceived that there was an 'embarrassing gap between theory and empirical research'. They proposed instead an inductive process in which theory is built and modified from the data collected. (Harding 2006, 131)

This statement reveals the efforts that have to be made for developing new theories inductively by using qualitative methods. Equally, by using grounded theory for answering the research question, the structure of this book will lead through the steps taken to develop a theory. Consequently, this book can also be seen as a small contribution to the discussion about possibilities of theory generation in general (Lamnek 2005, 101).

To illustrate the importance of new generations of theories, Glaser and Strauss describe in the preface of their first book "Awareness of dying" (1965) what they concentrated on in their research:

If increasingly Americans are dying within medical establishments, surrounded more by nurses and physicians than by kinsmen, then how do these representatives of the wider society manage themselves and their patients while the latter are dying? How is the hospital's organization capitalized upon in this process? What forms of social action, transitory or more permanent, arise while handling the dying of people? What are the social consequences for the hospital and its staff, as well as for the patients and their families? (Glaser and Strauss 1965, viii)

Developing a theory regarding this issue was of great importance to the researchers. The attempt to develop theories on social processes and developments in today's world is challenging. Yet, it can lead to insights that are useful for the future because they make processes transparent. Hence, conflicts and problems might be more easily identified, approached, and eventually solved.

With the child with disability at the centre of my investigation, grounded theory helped to focus on the processes and activities that take place in his/her surroundings and that affect the child's situation in his/her educational environment. Furthermore, I could place emphasis on reactions, feelings, perceptions and behaviour of the people in the immediate surroundings. Such possibilities lead to a com- 
pact set of data that can be combined and compared and finally lead to statements that enable outsiders to understand actions, reactions, behavioural patterns, etc. Those statements are supported by the experiences of a bigger group of people from various perspectives.

As grounded theory does not provide a theory at the beginning of a research process in the sense of offering a theoretical background, this research won't fulfil expectations of deductively proving existing theoretical assumptions, perspectives and points of view.

At the beginning of a research, researchers should approach the field of interest without biases, without predefined categories or hypotheses. However, it cannot be avoided that every researcher has background knowledge and experiences (Lamnek 2005, 106).

Furthermore, the area of field research should be one where not much research can be found yet because "Not much can be gained from energy expended to investigate issues that have already been explored extensively" (Birks and Mills 2011, 17). Therefore "[a]ll researchers should be able to demonstrate that their proposed study will generate knowledge that is relevant and significant" (Birks and Mills 2011, 17).

Birks and Mills mention three points that indicate that grounded theory is the best approach to working on a research project:

- Little is known about the area of study.

- The generation of theory with explanatory power is a desired outcome.

- An inherent process is imbedded in the research situation that is likely to be explicated by grounded theory methods. (Birks and Mills 2011, 16)

In other words, "new knowledge in the form of theory" will be the output of the research (Birks and Mills 2011, 16). The intention of the research at hand was to develop a theory from the information that was provided by the research participants and my own experiences and observations. In fact, little is known about factors that influence participation and activity of children with disabilities in educational environments in Addis Ababa. Last but not least, by looking at children with disabilities in primary schools, there are processes of developing relationships, inclusion, exclusion, dynamics between different actors (children, parents, teachers), etc. to be studied. The resulting categories that will lead to a final theory reveal a certain pattern. According to Glaser this pattern reflects the concept that has been studied (2010).

Yet, this is not to be misunderstood as a simple description of a process. Moving "analytical processes beyond simple description through exploration" (Birks and Mills 2011, 18) will lead to new insights into the issue of education for children with disabilities in a so-called developing country or country of the majority world. 


\section{Some More Insight into the Structures of the ICF}

In the field of special education, the approach to classification is extremely important because it reveals a great deal about dominant discourses and the underlying relationships of knowledge and power. From a social policy perspective, Kirp (1982) and others have noted that the way in which a social problem is described says a great deal about how it will be resolved. (Florian et al. 2006, 37)

The view of disability in the ICF and ICF-CY as a product of impairments of physical and mental structures and functions, activity limitations and participation restrictions in combination with environmental and personal factors seems promising for further developments within the research field of special needs education and inclusion. Unfortunately, the relation between the discourse on ICF/ICF-CY and the topical inclusive education is not very strong. However, the classification can be understood as a means that can be used in scientific as well as practicerelevant areas of special needs and inclusive education. Yet, Manser (2005) states that the ICF is neither meant to provide an additional instrument for analyses or observations nor does it offer a theory for inclusive or special needs education. Instead he describes the ICF as a technology that can be used to make the functional health of every person visible. Furthermore, he claims that the ICF has to be understood as a resource that can have different functions in different contexts (Manser 2005). Considering the ICF as a tool for multiple purposes, it can serve various approaches within special needs and inclusive education.

The ICF is split into two parts, each of which consists of further components. Part one deals with functioning and disability and includes body functions/body structures, activity and participation. The second part deals with context factors. This part comprises environmental factors and personal factors. The latter are not defined in detail in the classification (WHO and DIMDI 2005, 16). The different components of the classification stand in mutual dynamic relations that can influence the activity and participation of a person. Functioning and disability are thus constituted by the components body functions/body structures, activity and participation. Simultaneously, environmental and personal factors describe contextual aspects. In other words, functioning and disability are influenced by external environmental factors and internal personal factors. The environmental factors refer to two different levels: one concerning the individual (domestic area, school, workplace, social contacts) and one concerning society (structures and systems of the community) (WHO 2001, 2007). They influence all components of functioning and disability; they are arranged in the order of intensity of the relation between people and their environments, ranging from immediate to general environment (Hollenweger 2008; WHO 2001, 2007). In this research, Bronfenbrenner's bioecological model serves as a basis for describing and measuring the interplay between environment and human development at different stages. Environmental interactions may incorporate micro-, meso- and/or macro-systems in the course of an individual's lifespan (Bronfenbrenner 1980, 1999). This is integrated in the resulting models of this research. According to Simeonsson et al. (2008), environment as 
Table 4.1 ICF (WHO 2001)

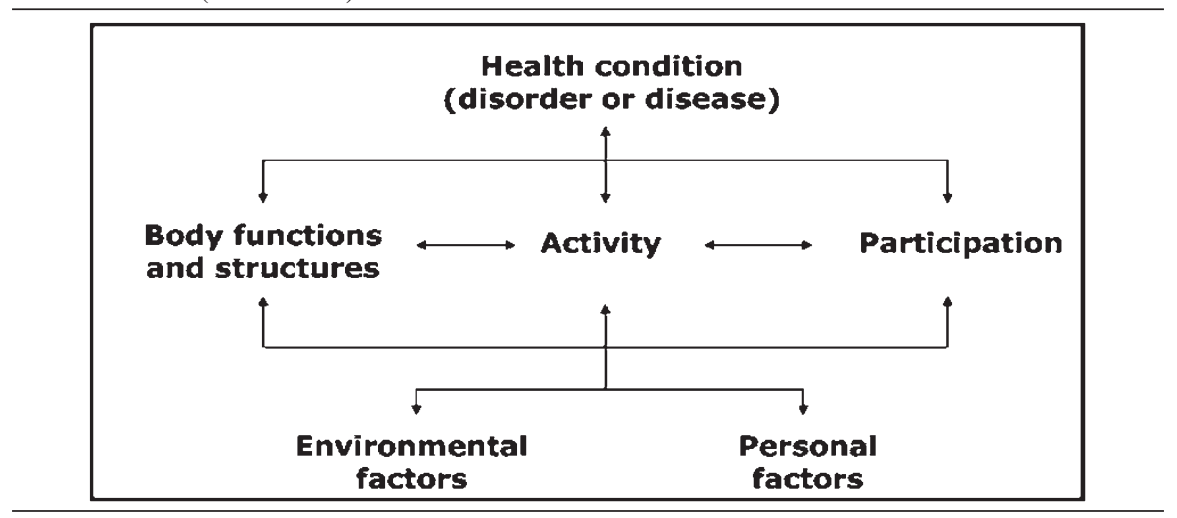

defined by Bronfenbrenner plays a key role in identifying possible supportive measures for children and adults. These might lead to enhanced participation within the school environment. According to the authors, an assessment of requirements within the school environment can contribute to an overall picture when using the coding system of the ICF/ICF-CY (see also Hollenweger 2008). Generally speaking, relations exist between all of these conceptual aspects. Hence, activity and participation can be supported or limited by the contextual factors (Table 4.1).

Hollenweger states that this approach opens new perspectives for special needs and inclusive education. She highlights that by using the ICF, foundations for new hypotheses and research questions have been established and dynamics between biological, psychological and social aspects of disability can be considered (2006, 51).

The ICF seems to provide a variety of possibilities to see disability in a context that includes environmental influences. Nevertheless, it can't be forgotten that there are still aspects within the classification that are not resolved satisfactorily. The chapter on environmental factors, for example, is relatively short compared to the other chapters and in need of further expansion. However, the awareness of the fact that the environment plays a decisive role regarding the construction of disability is of major importance. It has changed the interpretation of the questions of integration and inclusion fundamentally. Interventions can start by looking at the environment of a person with a disability rather than by looking at the person himself/ herself first. Disability is not understood as a characteristic of a person but as the result of the interaction between a person and the environment (Schneidert et al. 2003, 588).

Conducting research in different cultural environments is very challenging as the various backgrounds have a tremendous influence on constructions of disability. Thus the question remains if disability can be approached systematically on a global level and hence if the ICF can really be applied on an international and intercultural level (Chapireau 2005; Schiemer 2010). 
The ICF was used as a language for this research, although with constant awareness and reflection about possible insufficiencies regarding the culture and society studied. Therefore, the meanings of terms and phenomena have to be handled with utmost attention. The WHO states that the classification has to be seen in constant processes of development and that only research applying the instrument can eventually show its usability worldwide (Üstün et al. 2001; WHO 2001). The book at hand can be understood as a small contribution to this process as the ICF-CY has been used as a language and help for orientation to develop first research instruments for doing research in a foreign culture. In other words, the ICF-CY and the environmental factors of the classification have to be explored as a framework for this research in order to make the initial approach to the topic transparent.

Furthermore, the ICF-CY served as a framework for all three countries in the larger project. The chapter on environmental factors was used for developing guided interview guidelines and a questionnaire for the first phase of the field research. This indicates that the three-country project had been developed by using a mixedmethod approach. However, in the book at hand, I only applied qualitative methods. Yet, it is important to mention that a quantitative questionnaire was used for further studies, as it led to special situations in the field like spontaneous group discussions that were very fruitful for the qualitative research.

The ICF-CY provides five chapters regarding the environment:

1. Products and technology

2. Natural environment and human-made changes to environment

3. Support and relationships

4. Attitudes

5. Services, systems and policies (WHO 2007)

These chapters constituted the first basis for developing research instruments for the first of three phases of the field research. In the part on activities and participation, Chap. 8 of the ICF-CY is on "major life areas". Education is defined as one of these major areas. Code d820 indicates that education should include:

Gaining admission to school, education, engaging in all school-related responsibilities and privileges; learning the course material, subjects and other curriculum requirements in a primary or secondary education program, including attending school regularly; working cooperatively with other students, taking direction from teachers, organizing, studying and competing assigned tasks and projects, and advancing to other stages of education. (WHO 2007, 180)

However, in relation to educational areas and in combination with the participation of children, these points are defined quite vaguely (Biewer 2009a), making it necessary to elaborate an extension of the specific area of education and participation. Therefore, the study at hand goes beyond the use of the ICF-CY.

Against the background of the already mentioned discussions regarding international and intercultural concepts of disability, the ICF-CY has been used with reservation, as stated before. On the one hand, the gap in the definition related to education and participation of children (Biewer 2009b) makes it incomplete. On the other hand, the development of an international classification for disability gener- 
ally poses certain challenges. One of the most important points in this context is the before-mentioned claim of international and intercultural applicability (Chapireau 2005; Üstün et al. 2001). The cautious position regarding the use of the ICF-CY is hence also to be understood as a critical objection towards this claim. At least, there are recognised differences regarding the interpretation of the phenomenon "disability" as such in different cultures (Ingstad and Whyte 1995) as well as cultural differences regarding the aspects that are involved in a definition of disability, as already indicated in the chapters above. Furthermore, even if similar aspects are involved, they might have different meanings and importance in different societies and hence have to be given respective weight or neglect. This is the reason why it is important to find out about the category or concept of disability and its meaning in a certain culture. Furthermore, it is important to consider which consequences certain perspectives and models of disabilities might imply before the system of the ICF-CY can be used. Such a procedure can indicate the usefulness or uselessness of applying parts of the classification in certain environments. For the research at hand, the environmental factors in the ICF-CY provided me with an optimal starting point in regard to the initial research question. This makes clear that it is advisable and even necessary to use only the parts of the classification that make sense for the respective case.

However, especially the area of education represents a sensitive zone regarding classification and labelling. A problematic issue could develop unintentionally from an overidentification of children belonging to marginal groups. This again could lead to lower expectations towards this group and forward a system of separation (Florian et al. 2006, 37). Classifying children in the educational system in order to satisfy political demands and to have a basis for the request of resources is a dangerous proceeding. Such an approach can have consequences for the lives of children that cannot be foreseen. Furthermore, [...] a universal system of classification or categorization in education does not exist. In practice, various approaches are used, and these may be based on different assumptions about human difference and disability (Florian et al. 2006, 37). This again underscores the caution that has to be taken when using classification systems in general and the ICF-CY in particular when working in the area of education. It also explains why the ICF-CY could only be used as a starting point and was not employed as general instrument throughout the research.

\section{An Example of the Limited Power of the ICF-CY}

The use of the ICF-CY for developing the first research instruments was helpful as questions around thematic blocks could easily be created for interview guidelines and a pool of questions. It served as a functional basis to support me in covering the main aspects of educational environments for children with disabilities. At the end of the research, the question came up, how single aspects of "developing a sense of belonging" would be interpreted by the ICF-CY. 
Considering the environmental factors of the ICF-CY, the codes that would probably be used for some of the main aspects of the results would be related to Chaps. 4 and 5 of the classification: "relationships and support" and "attitudes". Both of these chapters are not very extensive. The codes that are suggested to be used in these cases are equipped with a qualifier that indicates if the respective code is, e.g. no barrier or a complete facilitator for a person or situation, offering eight different nuances between the two poles of barrier and facilitator. Additionally there are "not specified" qualifiers (WHO 2007, 189f.). For example, the code "e310: Immediate family" could be coded as e $310+3$ " meaning that the immediate family is a substantial facilitator for the child. This makes clear what kind of information can and cannot be communicated by using the ICF-CY in relation to environmental factors. It is not detailed or extensive information and can only be used in a very restricted way. Only being able to make statements about the intensity of family being a facilitator or barrier does not explain the reasons nor consequences of this fact and hence can only provide very limited information about the environment of a child. Consequently, the explanatory power about the special needs a child with a certain disability (or health condition, using the terminology of the ICF/ICF-CY) in his/her educational environment is also limited.

In short, there are problems in defining and providing for the significant numbers of disabled children and youth many of whom are excluded from educational opportunities for primary and secondary schooling. The usefulness of categorical classifications of disability is being questioned in terms of their cost-effectiveness and their ability to identify needed services. Environmental factors play a significant role in disabling the vast majority of students. (Peters 2007, 120)

Regarding inclusive education, the ICF-CY is still not a language that can be internationally applied satisfactorily. Even though some scholars suggest that the classification can be used to provide people with an overall picture about certain requirements within a school environment (Hollenweger 2008; Simeonsson et al. 2008), restrictions become evident.

In this context it may be legitimate to ask in which ways the ICF can be relevant for the case of Ethiopia. It would be very revealing to learn which items are missing to be able to include all important functionings of a child who wants to participate and be involved in his/her community life in Ethiopia. The ICF was invented to offer a language for describing the functioning of a person. This language should serve for enabling scientists and other experts to exchange and use information on an interdisciplinary level. The challenge at this point is that a language has to be learnt before it can be used, which already poses serious problems, as projects involving the ICF in Italy can tell (De Polo et al. 2009).

It is indeed difficult to determine the relevance of the ICF in Ethiopia, as I couldn't find published, or otherwise accessible, examples of its use. This brings us back to the study of Üstün et al. (2001), who stated that the ICF can be used interculturally. However, I doubt that we always should use it. Is using the ICF really suitable for any cultural context? Isn't it possible that using such a classification undermines values in certain cultures and leaves black spots on important issues? For example, the chapter on environmental factors in the ICF is not as extensive as 
other chapters. In the case of the study at hand, in which the environment of family and community plays such an important role, it might just not cover enough aspects. Moreover, existing structures may be far better for enabling all people of a community to participate in an inclusive way.

My conclusion so far is that from an outside perspective, using the ICF may be helpful (for doing research or collecting data for estimating needs...). But inside an Ethiopian community itself, the ICF may exhibit many inadequacies and restrictions, thus failing to lead to the expected results. As a supporting tool, the capability approach could be a possibility to get closer to the real needs of the people.

\section{Ethical Concerns}

In recent years, a greater focus on cross-cultural research and on research undertaken by multidisciplinary national teams has raised significant challenges with regard to how educational research is conceptualised, conducted and disseminated in an ethical manner. (Robinson-Pant and Singal 2013, 417)

Issues that are usually discussed in research literature on ethics are aspects of consent, confidentiality, ownership and power relations. We should be aware also in the context of the ICF that certain power relations develop by simply using predefined codes to describe certain environments of a person (insufficiently, as described above). It seems that aspects of the power relation which develops between the researcher and interviewees mark the starting point of ethical considerations in research in general (Marshall and Batten 2004; Powell 2011). Since these points are crucial for the research at hand, this chapter aims at addressing major aspects that are perceived as important regarding ethical implications for this book; these are children, vulnerable groups, informed consent, cultural differences and power relations.

Many of the people involved in the study at hand did not have concepts of science or research and might not know about their rights to refuse an interview or withdraw their consent. However, I always pointed out the possibility to withdraw the given consent. Especially interviews with children had to be conducted with utmost empathy but, above all, with their informed consent (Carter 2009; Eder and Fingerson 2003; Grob-Paeprer and Podlesch 2000; Roberts 2008). This required explaining clearly what the purpose of the study, the possible impact, issues about anonymity, etc. were. In the research at hand, the informed consent to conducting interviews included consent on taking pictures and collecting any other material related to the children. In addition to the child's consent, the consent of the parents or caretakers was collected before the child was interviewed. It is natural that challenges arise when trying to explain the research aims and possible consequences to the different groups. This leads to ethical concerns for the researcher. Lewis (2002) identifies six areas of concern regarding interviews with children. These are access and gatekeepers to reach the children, the children's consent and assent for conducting the interview, confidentiality, anonymity and secrecy regarding the handling of 
gathered information, recognition and feedback, ownership and social responsibility regarding the usage of the data (Lewis 2002, 110f). All of these areas are of major importance when interviewing children and have to be regarded accordingly. Discussions about ethics in research also involve the terminology of vulnerability and vulnerable groups. According to Solomon (2013), there are two groups of vulnerable research participants: the ones who are cognitively and the ones who are economically vulnerable. For this research it is especially the group of cognitively vulnerable participants, who are not able to decide deliberately if they want to participate in the study or not. In this context, children can be defined as especially vulnerable, as their decisions might be influenced by adults. However, children should be given the possibility to speak for themselves if they wish to do so.

\begin{abstract}
Children have historically been marginalized in research with proxies used as appropriate sources of information about children's experiences, perceptions and understandings. In the context of research governance and ethical review, the default setting in many countries reflects a long history of framing children within a discourse of vulnerability and seeing research with (or on) children as inherently risky. This perspective inevitably positions researchers as '(potentially) dangerous' and requires reviewers to adopt a (super-) cautious approach to any research proposal involving children's participation. (Carter 2009, 858)
\end{abstract}

Even though some of the children showed that they decided for themselves by refraining from participating in this study, it can never be said if they really understood the whole context. ${ }^{1}$ However, as Carter correctly indicates, "the discourse of child vulnerability competes with the discourse of child participation and involvement" $(2009,858)$. In the case of this study, it would have been paradox not to involve children, as the whole research framework dealt with inclusion, participation and activity of children with disabilities. Therefore, it was of utmost importance to involve the children, listen carefully to their needs and messages and react accordingly. In doing so, it was indispensable to involve an Ethiopian researcher, who had experience in interviewing children and showed empathy throughout the interviews. ${ }^{2}$ There might be an additional concern about interviewing children with disabilities and in particular children with intellectual disabilities. A number of publications explore this issue (Aarons et al. 2004; Grob-Paeprer and Podlesch 2000; Lewis 2002, Odom et al. 2004).

As far as the parents are concerned, some - despite repeatedly explaining the opposite to them - continued to believe that I was sent by an NGO in order to support their child. This became clear during consecutive interviews in which they started to speak about support they expected from us. The parents therefore seemed

\footnotetext{
${ }^{1}$ Yet, this is also the case for any of the participants.

${ }^{2}$ It has to be considered that by involving an Ethiopian researcher, cultural and societal values and norms that possibly restrict free speech of children might also be imported to the interview situation. This would be the case if children are not seen as capable or mature enough to speak for themselves. Even though this perception can be found in the Ethiopian culture, the research team tried to encourage the children to speak freely. On the other hand, a person with a Western background (skin color, language, behaviour etc.) might also influence the course of the interviews to a certain extent. Hence, having a local and a non-local researcher in the team can be considered as a good precondition for overcoming those challenges by including emic as well as etic perspectives.
} 
to belong to the group of the economically vulnerable, as they expected that support would be provided because of their participation. This shows that it can be very challenging to communicate research purposes and issues concerning the ongoing process of field research, etc. This was the case despite the fact that the research team included an Ethiopian researcher with an emic perspective. Aspects that have to be considered beyond informed consent while conducting research in different cultures are cultural and ethical differences.

The implication for researchers rests in not adhering to any universal ethic in designing and conducting research, while simultaneously attempting to respect the particular and contextual ethical norms of a given social or ethnic group. Flexibility on the part of the researcher may be one way to deal with such cultural norm differences. (Marshall and Batten 2004)

This statement makes it clear that the field research was a balancing act for me, as I had to react flexibly to different situations. Correspondingly, the research activity was partially learning by doing, as many situations that arose could not be predicted, which made preparation difficult.

A last point that has to be mentioned regards the power relations which were mentioned at the beginning of this chapter. In this respect, it is important for me as a researcher to be aware of the power relations between me and the participants. Especially in the setting of this research study, where I am of European descent (but also female and without an obvious disability apart from reduced eyesight), it was essential to be aware of the impact and consequences that this circumstance might have on the interview situation in general and on the participants in particular. However, not only power relations on this level have to get attention. As the research was conducted with the participation of colleagues from Addis Ababa University, there were also dynamics that have to be taken into account on this level.

When those in privileged positions and in wealthier countries consider undertaking collaborative research with colleagues in developing countries it is necessary to understand both their own framework of thinking, and the implications of very different mind-sets and environments in which research projects may be carried out in developing countries. (Benatar 2002, 1132)

Thus, understanding new frameworks and ways of thinking was one of the most important tasks for me at the beginning as well as throughout the research project. In this regard it was helpful to work very closely with the Ethiopian team and especially with my research assistant. I highly valued considerations and advice from the Ethiopian side, and - when possible - I tried to adapt the research activities accordingly. This shows that it is very important to consider the cultural environment in which research is conducted. This environment might have ethical issues that are different to the ones that I might consider when coming from a minority world background. Therefore, this chapter is concluded with the following statement:

The ethical issues in the literature regarding research in the Majority world context clearly have significant ramifications for cross cultural research. Ethical issues have different resonances in different world contexts, and research planned and undertaken in Majority world countries challenges assumptions underlying Minority world ethical guidelines. (Powell 2011,3) 

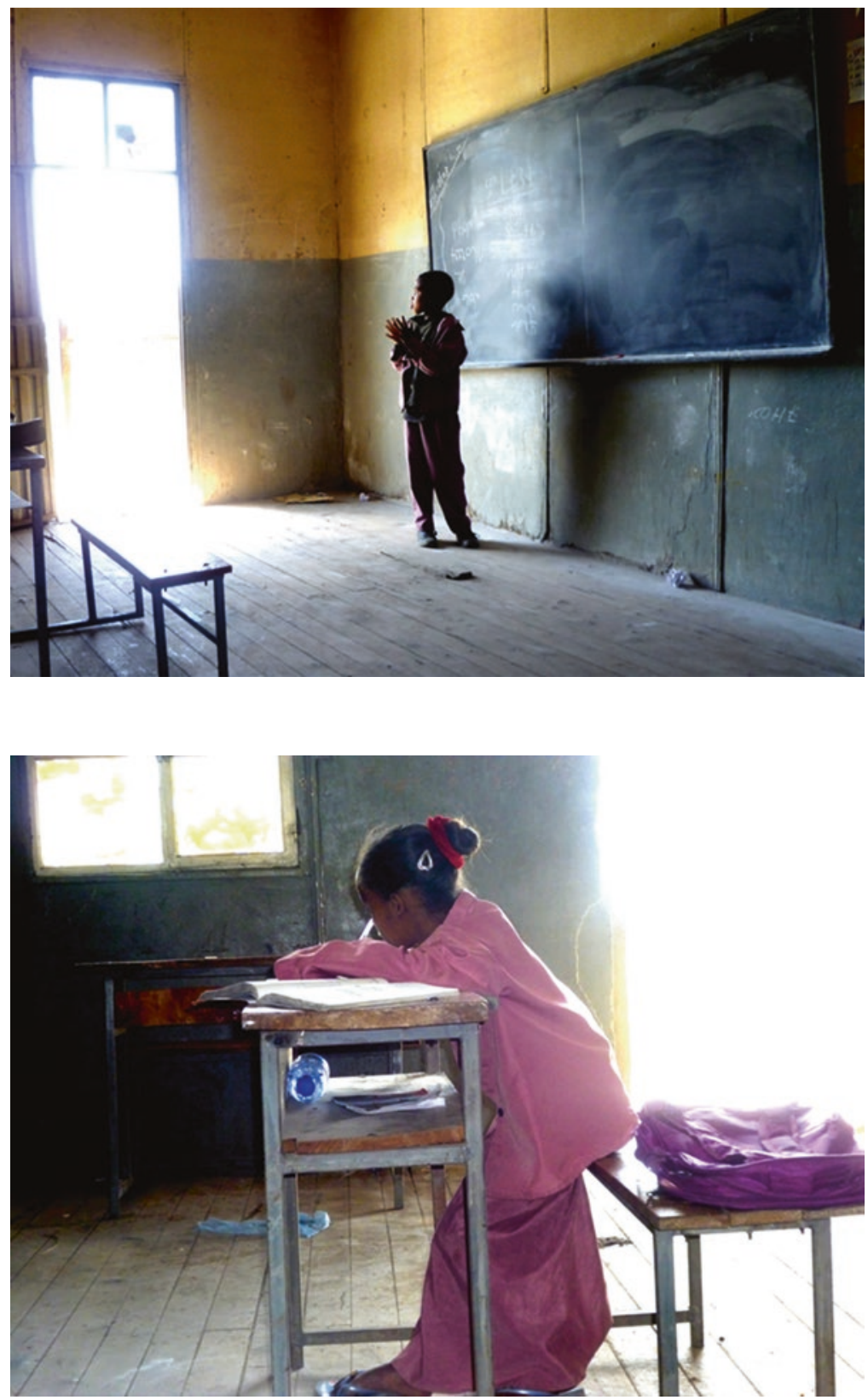

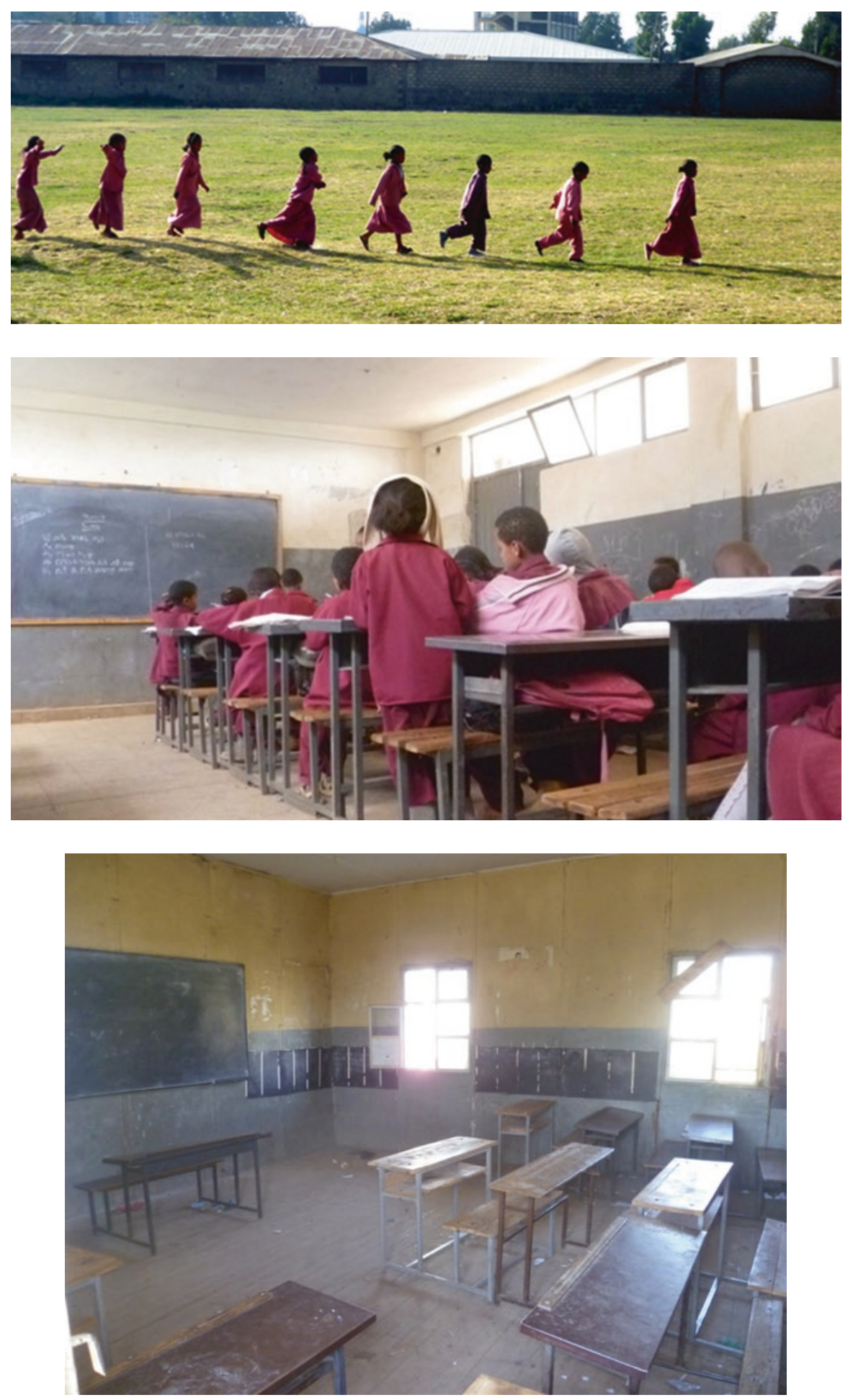


\section{References}

Aarons, N. M., Powell, M. B., \& Browne, J. (2004). Police perceptions of interviews involving children with intellectual disabilities: A qualitative inquiry. Policing and Society, 14(3), 269-278.

Benatar, S. R. (2002). Reflections and recommendations on research ethics in developing countries. Social Science \& Medicine, 54(7), 1131-1141.

Biewer, G. (2009a). Grundlagen der Heilpädagogik und Inklusiven Pädagogik. Bad Heilbrunn: Klinkhardt.

Biewer, G. (2009b). Vom Verschwinden der Etiketten zum Verlust der Inhalte. Heilpädagogische Klassifizierung im internationalen Vergleich. In A. Bürli, U. Strasser, \& A. D. Stein (Eds.), Integration/Inklusion aus internationaler Sicht (pp. 169-176). Bad Heilbrunn: Klinkhardt.

Birks, M., \& Mills, J. (2011). Grounded theory. A practical guide. Los Angeles/London/New Delhi/Singapore/Washington, DC: Sage.

Bronfenbrenner, U. (1980). The ecology of human development. Experiments by nature and design. Cambridge: Harvard University.

Bronfenbrenner, U. (1999). Environments in developmental perspective: Theoretical and operational models. In S. L. Friedman \& T. D. Wachs (Eds.), Measuring environment across the life span. Emerging methods and concepts (pp. 3-28). Washington, DC: American Psychological Association.

Bryant, A., \& Charmaz, K. (2007). Introduction. Grounded theory research: Methods and practices. In A. Bryant \& K. Charmaz (Eds.), The sage handbook of grounded theory (pp. 1-28). Los Angeles/London/New Dehli/Singapore: Sage.

Carter, B. (2009). Tick box for child? The ethical positioning of children as vulnerable, researchers as barbarians and reviewers as overly cautious. International Journal of Nursing Studies, 46(6), 858-864.

Chapireau, F. (2005). The environment in the international classification of functioning, disability and health. Journal of Applied Research in Intellectual Disabilities, 18, 305-311.

Charmaz, K. (2006). Constructing grounded theory: A practical guide through qualitative analysis. London/Thousand Oaks/New Delhi: Sage.

Charmaz, K. (2009). Shifting the grounds: Constructivist grounded theory methods. In J. M. Morse (Ed.), Developing grounded theory. The second generation (pp. 127-154). Walnut Creek: Left Coast Press.

De Polo, G., et al. (2009). Children with disability at school: The application of ICF-CY in the Veneto region. Disability and Rehabilitation, 31(S1), 67-73.

Eder, D., \& Fingerson, L. (2003). Interviewing children and adolescents. In J. A. Holstein \& J. F. Gubrium (Eds.), Inside interviewing (pp. 33-53). Thousand Oaks et al.: Sage.

Florian, L., et al. (2006). Cross-cultural perspectives on the classification of children with disabilities: Part I. Issues in the classification of children with disabilities. Journal of Special Education, 40(1), 36-45.

Glaser, B. (2010). Grounded theory is the study of a concept. (Youtube, Glaser, B.). Retrieved November 23, 2016, from http://www.youtube.com/watch?NR=1\&v=OcpxaLQDnLk\&featu re $=$ endscreen

Glaser, B., \& Strauss, A. (1965). Awareness of dying. Chicago: Aldine Transaction.

Glaser, B. G., \& Strauss, A. L. (1967/2008). The discovery of grounded theory: Strategies for qualitative research. New Brunswick: Aldine Transaction.

Grob-Paeprer, B., \& Podlesch, W. (2000). Forschen bei Kindern mit geistiger Behinderung und Kindern mit schwerer Mehrfachbehinderung. In F. Heinzel (Ed.), Methoden der Kindheitsforschung. Ein Überblick über Forschungszugänge zur kindlichen Perspektive (pp. 265-278). Weinheim/München: Juventa. 
Harding, J. (2006). Grounded theory. In V. Jupp (Ed.), The sage dictionary of social research methods (pp. 131-132). London/Thoudand Oaks/New Delhi: Sage.

Hollenweger, J. (2006). Der Beitrag der Weltgesundheitsorganisation zur Klärung konzeptueller Grundlagen einer inklusiven Pädagogik. In M. Dederich, H. Greving, \& P. Rödler (Eds.), Inklusion statt Integration? Heilpädagogik als Kulturtechnik (pp. 45-61). Gießen: Psychosozial.

Hollenweger, J. (2008). Cross-national comparisons of special education classification systems. In L. Florian \& M. J. McLaughlin (Eds.), Disability classification in education. Issues and perspectives (pp. 11-30). Thousand Oaks: Corwin Press.

Ingstad, B., \& Whyte, S. R. (Eds.). (1995). Disability and culture. Berkeley/Los Angeles/London: University of California Press.

Kirp, D. (1982). Professionalism as policy choice: British special education in comparative perspective. World Politics, 34, 137-174.

Lamnek, S. (2005). Qualitative Sozialforschung. Lehrbuch. Weinheim: Beltz.

Lewis, A. (2002). Accessing, through research interviews, the views of children with difficulties in learning. Support for Learning, 17(3), 110-116. Library of Congress Glossary Ethiopia. Retrieved March 8, 2014, from http://lcweb2.loc.gov/frd/cs/ethiopia/et_glos.html. (not available anymore).

Manser, R. (2005). ICF und ihre Anwendung in der Heilpädagogik. Ein kritischer Diskurs. In H. Dohrenbusch (Ed.), Differentielle Heilpädagogik (pp. 25-54). Luzern: Edition SZH/ CSPS.

Marshall, A., \& Batten, S. (2004). Researching across cultures: Issues of ethics and power. Forum Qualitative Sozialforschung/Forum: Qualitative Social Research. Retrieved November 23, 2016, from http://www.qualitative-research.net/index.php/fqs/article/view/572/1241

Odom, S. L., et al. (2004). Investigating inclusion: A review of research mehods for individuals with intellectual disability. In E. Emerson et al. (Eds.), The international handbook of applied research in intellectual disabilities (pp. 281-295). Chichester: Wiley.

Peters, S. (2007). Inclusion as a strategy for achieving education for all. In L. Florian (Ed.), The sage handbook of special education (pp. 117-130). London/Thousand Oaks/New Delhi: Sage.

Powell, M. A. (2011). International literature review: Ethical issues in undertaking research with children and young people (literature review for the childwatch international research network). In Lismore/Dunedin, Southern Cross University, Centre for Children and Young People/University of Otago, Centre for Research on Children and Families.

Roberts, H. (2008). Listening to children: And hearing them. In P. Christensen \& A. James (Eds.), Research with children. Perspectives and practices (Vol. 2, pp. 260-275). Oxon/New York: Routledge.

Robinson-Pant, A., \& Singal, N. (2013). Researching ethically across cultures: Issues of knowledge, power and voice. Compare: A Journal of Comparative and International Education, 43(4), 417-421.

Schiemer, M. (2010). ICF - Instrument für eine interkulturell vergleichende Heilpädagogik? In U. Schildmann (Ed.), Umgang mit Verschiedenheit in der Lebensspanne. Bad Heilbrunn: Klinkhardt.

Schneidert, M., et al. (2003). The role of environment in the international classification of functioning, disability and health. Disability and Rehabilitation, 25(11-12), 588-595.

Simeonsson, R. J., et al. (2008). International classification of functioning, disability and health for children and youth. A common language for special education. In L. Florian \& M. J. McLaughlin (Eds.), Disability classification in education. Issues and perspectives (pp. 207226). Thousand Oaks: Corwin Press.

Solomon, S. R. (2013). Protecting and respecting the vulnerable: Existing regulations or further protections? Theoretical Medicine and Bioethics, 34(1), 17-28.

Üstün, T. B., et al. (Eds.). (2001). Disability and culture. Universalism and culture. ICIDH-2 series. Published on behalf of the world health organisation. Seattle: Hofgrefe \& Huber. 
WHO. (2001). International classification of functioning, disability and health. Geneva: World Health Organization.

WHO. (2007). International classification of functioning, disability and health. Children \& youth version. Geneva: World Health Organization.

WHO \& DIMDI. (2005). Internationale Klassifikation der Funktionsfähigkeit, Behinderung und Gesundheit. Genf: Deutsches Institut für Medizinische Dokumentation und Information (DIMDI).

Open Access This chapter is licensed under the terms of the Creative Commons Attribution 4.0 International License (http://creativecommons.org/licenses/by/4.0/), which permits use, sharing, adaptation, distribution and reproduction in any medium or format, as long as you give appropriate credit to the original author(s) and the source, provide a link to the Creative Commons license and indicate if changes were made.

The images or other third party material in this chapter are included in the chapter's Creative Commons license, unless indicated otherwise in a credit line to the material. If material is not included in the chapter's Creative Commons license and your intended use is not permitted by statutory regulation or exceeds the permitted use, you will need to obtain permission directly from the copyright holder.

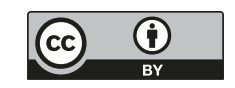

